\title{
Demand Forecast, Supply and Equilibrium Price on the Deposit Market: Methodology and Experience of Ukraine
}

\section{Iryna Didenko}

$\mathrm{PhD}$, Assistant of the Department of Finance, Banking and Insurance, Sumy State University, Sumy, Ukraine

Hiba Fouad Hammadi

Senior Tax Controller, Lebanese Ministry of Finance AND university Instructor Instructor of Finance \& Accounting, Lebanon

\begin{abstract}
The purpose of the article is to conduct forecasting of demand, supply and equilibrium prices on the deposit market of Ukraine, which provides for a refinement of the criteria base for the selection of forecasting methods (taking into account world experience, the reporting system and the course of financial sector reform in Ukraine) and indicators for estimating the quality of the forecast taking into account the complexity of the sample and time lag. This has made it possible to study the peculiar features of the periods of functioning of the deposit market of Ukraine in equilibrium and formalize the functional dependencies for forecasting demand, supply and equilibrium interest rates in this market, taking into account the detected time lags.
\end{abstract}

Keywords: deposits, deposit market, demand, supply, equilibrium price.

JEL Classification: E37.

(C) The Authors, 2017. This article is published with open access at ARMG Publishing.

\section{Introduction}

One article has conducted the evaluation of supply and demand on the deposit market of Ukraine and determined equilibrium (Lyeonov and Didenko, 2017). The conducted analysis of key factors influencing the state deposit market situation was singled out seven most relevant. Having established a functional relationship between them, an equilibrium rate on the deposit market of Ukraine was obtained, which is $7.82 \%$. During the investigated period of 2005 - 2016 the market was balanced three times. This equilibrium was short-lived, indicating an unstable state of the domestic deposit market. The Ukrainian deposit market during 2005 - II quarter of 2016 was revealed to a large extent represented by funds of individuals, whose share in total deposits exceeds even $50 \%$. The prevalence in the general structure of deposits is short (on request) shows still insufficient confidence in the domestic deposit market. In terms of the foreign exchange component of the deposit portfolio of Ukraine, the share of deposits in national currency was higher over the past ten years. For the analysis of interest rates in the deposit market of Ukraine was elected weighted average cost of time deposits in the local currency. It is possible to predetermine in what state the deposit market is located with the help of this rate (Fig. 1). Usually the main reference point for setting the deposit rate is the discount rate of the National Bank of Ukraine (NBU) as the primary price of issuing money by the central bank in circulation. In other words, by dint of the discount rate you can manage the supply of money.

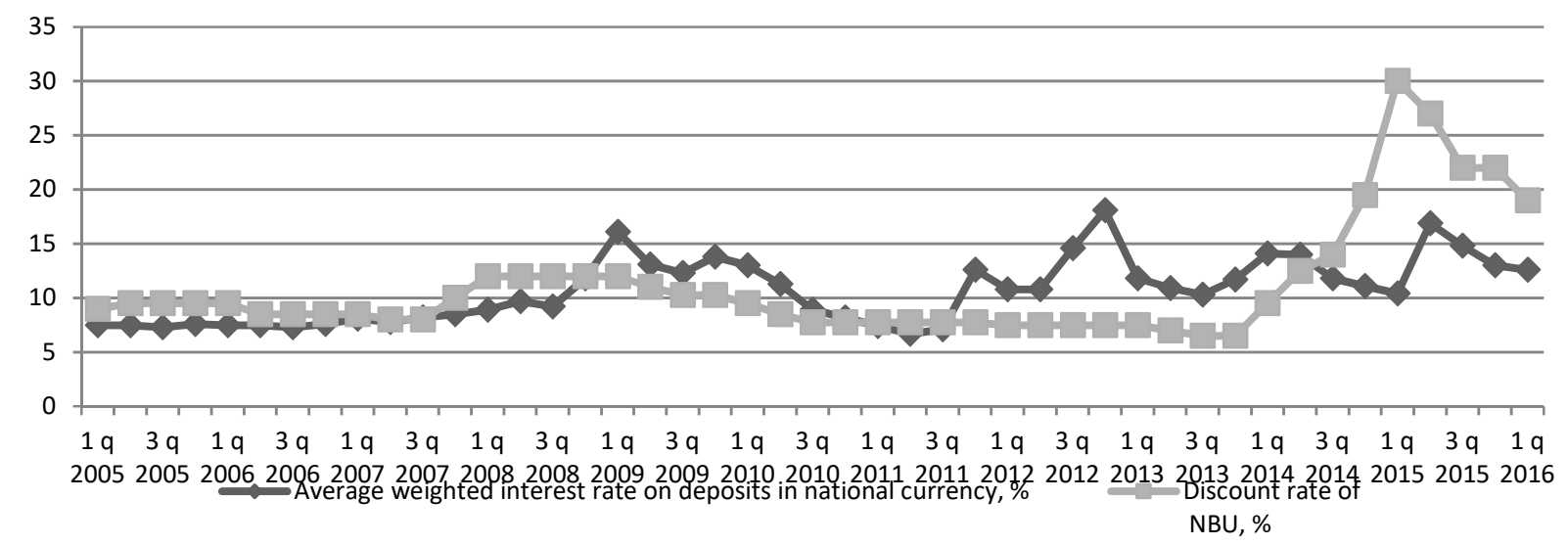

Figure. 1. Changes in the weighted average interest rate on deposits in the national currency by a ratio of change NBU discount rate during 2005 and the first quarter of 2016, calculations for Ukraine 
The average weighted interest rate on term deposits in national currency with changes in the NBU discount rate is gradually going to increase.in the second quarter of the crisis in 2008 (Fig. 1). Then, on the beginning 2014 we have seen discontinuous variation in interest rates on deposits, which are relatively proactive quality of the change NBU discount rate. In addition, for this period, the maximum and minimum interest rate on deposits is $18.1 \%$ in the fourth quarter of 2012 and $6.8 \%$ in the 2 nd quarter of 2011, respectively. This discontinuity between the minimum and maximum values for such a short time demonstrates an instability in the deposit market of Ukraine. The pronounced upswing in the discount rate in 2015 to the level of 30\% was made to regulate inflation in the country. However, as practice shows, by dint of a discount rate, it is not always possible to achieve the expected result in the management of both credit and deposit rates. According to domestic bankers, now, in order to reduce interest rates on deposits, the NBU should sharply reduce the discount rate to $10-12 \%$, and thus reorient banks for the issuance of loans, rather than investing resources in NBU deposit certificates. According to experts, by the end of 2016 is expected to reduce interest rates on deposits by $1.5-3 \%$.

All these aspects indicate that the conditions for attracting foreign funds in banks do not meet the needs of the population and business entities.

The implementation of a number of reforms of the Ukrainian banking system in the context of the Ukraine 2020 program at the final stages envisages the completion of its "clearing" and "reloading" processes. Since the implementation of these reforms is already coming to an end it is appropriate to check on how well they hold. For this we calculate the predicted values of the demand, supply and equilibrium price in the market and whether ensure in conducted reforms.

Fundamental principles of assessment and forecasting of the deposit market laid such foreign scholars as Craig B. (B. Craig), AG-Knut Demiurgic (A. Demirguc-Kunt), B. Dinher (V. Dinger), A. Dick (A. Dick), S. Kanoh, J. Panzar, J. Rosse, S. Sovago, V. Xavier (V. Xavier) and others.

\section{Methods and Result}

Since the implementation of the reform of the "purge" of the banking system is scheduled for the end of 2016, we will predict the behavior of the deposit market in II, III, IV quarters of 2016 and I quarter 2017. Taking the specific inputs that were used in the modeling of supply and demand and the number of forecast data you want to get, we elected to nine different prediction methods:

- extrapolation based on the middle level of the rage;

- extrapolation by average total addition;

- extrapolation at an average rate of increasing;

- extrapolation based on the increasing curve;

- method of exponential smoothing based on the middle level of the rage;

- method of exponential smoothing based on the middle level of the rage;

- Braun's model of the 1st order;

- Braun's model of the 2nd order;

- Holt's model.

Among the methods of forecasting we propose the simplest approach that determines the predictive value, based on the actual level by calculating the following statistical indicators:

- the average value of range;

- the average absolute growth;

- the average growth rate.

- Methods for forecasting each of these methods consider in more detail.

Prediction by the mean value of a rage is also called a point prediction. This name is due to the fact that the predictive value of any of the studied parameters assumed to be the arithmetic mean of the indicator over time.

The main disadvantage of this method of forecasting is that it is not considered an essential condition for some value of the index may fluctuate around the mean value in the past, but under the influence of a set of different factors that cannot be in the future. Therefore, using this method it is imperative to assess the prospects of the dynamics of the change in the investigated indicator.

Predictive estimate $\tilde{y}_{n}(\tau)$ at average implicit increment be counted according to the formula: 
$\tilde{y}_{n}(\tau)=y_{n}+\tau \cdot \Delta \bar{y}$

where $\Delta \bar{y}$ - average total increment.

In this context the total increment represents the difference between each previous and the present value of the index. Predictive estimate $\tilde{y}_{n}(\tau)$ by the average tempo growth

$\tilde{y}_{n}(\tau)=y_{n} \cdot \bar{T}_{3 p}^{\tau}$

where $\bar{T}_{3 p}^{\tau}$ - the average tempo growth calculated on the average geometry. Other methods of forecasting we have united into a group of algorithmic methods. The peculiarity of their use is that there is a successive replacement of the actual values of the series under study with values that are smoothed out by a certain algorithm. Thus, the algorithmic model is constantly adapted to change the data, which is reflected in the final result, as the last tendency of the change of indicator is taken into account.

Let's dwell in detail on this group of methods of forecasting. In order to predict the value based on the choice of the growth curve, it is necessary to correctly determine the form of this curve. In other words, it is necessary to analytically determine the dependence of the values of the indicator on time or to establish its trend. In this case, he must satisfy the conditions:

be theoretically grounded;

- have a small number of parameters;

- all parameters can be explained from an economic point of view;

- the constructed trend should not differ significantly from the initial values of the indicator.

Often, in the context of the method of pre-selection of the growth curve, mention is made of the method of the characteristics of growth, since it is considered universal in this category. Its essence lies in the use of certain characteristic features of the curves.

First, the input values of the indicator need to be preliminarily smooth using the simple average variable method. For smoothing the interval $\mathrm{m}=3$ adjusted level calculated as follows:

$\bar{y}_{t}=\frac{y_{t-1}+y_{t}+y_{t+1}}{3}$

For saving the first and last value of the researched indicator, we smoothing them as follows: $\bar{y}_{t}=\frac{-y_{t-2}+2 y_{t}+5 y_{t+1}}{6}$

Smoothing out the original number, you need to identify intermediate indicators, and then build their schedules and then make appropriate conclusions about the kind of growth curve to be used in the prediction (Table. 1).

Table 1. The choice of curve increment, calculations for Ukraine

\begin{tabular}{|c|c|c|}
\hline Intermediate Indicator & Character of changing Intermediate Type & The type of growth curve \\
\hline $\begin{array}{c}\text { The first average increment } \\
\left(\bar{\Delta}_{t}=\frac{\bar{y}_{t+1}-\bar{y}_{t-1}}{2}\right)\end{array}$ & Almost identical / varies linearly & Direct / Parabola \\
\hline $\begin{array}{c}\text { The first average increment } \\
\left(\bar{\Delta}_{t}^{2}=\frac{\bar{\Delta}_{t+1}-\bar{\Delta}_{t-1}}{2}\right)\end{array}$ & Varies linearly & Cubic parabola \\
\hline$\frac{\bar{\Delta}_{t}}{\bar{y}_{t}}$ & Almost the same & Simple exponent \\
\hline
\end{tabular}


Table 1 (cont.). The choice of curve increment, calculations for Ukraine

\begin{tabular}{|c|c|c|}
\hline Intermediate Indicator & Character of changing Intermediate Type & The type of growth curve \\
\hline $\log \bar{\Delta}_{t}$ & Varies linearly & Modified Exhibitor \\
\hline $\log \frac{\bar{\Delta}_{t}}{\bar{y}_{t}}$ & Varies linearly & Gompert's Curve \\
\hline $\log \frac{\bar{\Delta}_{t}}{\bar{y}^{2}}$ & Varies linearly & Logistic curve \\
\hline
\end{tabular}

The assessment is built on this method as follows:

$\hat{y}_{t+1}=\alpha \cdot y_{t}+(1-\alpha) \cdot \hat{y}_{t}$,

where $y_{t}-$ real value in the previous period;

$\hat{y}$ - the assessment value in the previous period.

Thus, in order to calculate the new exponential mean, it is necessary to take the preliminary value of the exponential average and, accordingly, the proportion of the difference between the previous indicator and its smoothed value.

The next method of forecasting we chose in our work is Brown's method. This method is otherwise called the generalized method of simple exponential smoothing. It is generalized by choosing the degree of polynomial (degree) of the study. Let's consider how they are being built.

The zero-order model displays a time range $y_{t}(t=1,2, \ldots, n)$, where trend and seasonal fluctuations are absent:

$y_{t}=a_{0}+\varepsilon_{t}$,

where $a_{0}$ - unknown independent time parameter that characterizes the current level range.

The first-order model is described by the following formula:

$y_{t}=a_{0}+a_{1} \cdot t+\varepsilon_{t}$,

where $a_{0}$-parameter whose value characterizes the average of the last level of range;

$a_{1}$ - parameter characterizing the growth end of the observation period, and (although to a lesser extent) the rate of growth in previous periods.

A model displays a second order parabolic trend and is constructed as follows:

$y_{t}=a_{0}+a_{1} \cdot t+\frac{1}{2} a_{2} \cdot t^{2}+\varepsilon_{t}$

where $a_{2}$ - parameter which characterizes the current value increase or acceleration.

After choosing the order of the model it is necessary to conduct an analysis according to the following algorithm:

- $\quad$ determining initial values of model parameters $\left(a_{0}, a_{1}, a_{2}\right.$ depending on the model order) by the method of least squares, using 10 - 15 first observations.

- $\quad$ - calculation of the assessment value for one subsequent period, using the formulas $y_{t}=a_{0}$ або $y_{t}=a_{0}+a_{1} \cdot t$, or $y_{t}=a_{0}+a_{1} \cdot t+\frac{1}{2} a_{2} \cdot t^{2}$ (depending on the type of model) for $t=1$.

the choice of the smoothing parameter $\beta$ (discount factor), the optimal value of which lies within $[0$; 1]. This parameter is analogous to the parameter $\alpha$ determined by the numerical optimization method and remains unchanged throughout the research process.

- calculation of assessment error according to the formula: $e_{t}=y_{t}-\hat{y}_{t}$. - calculation of the corresponding parameters for the chosen model of Brown.

- $\quad$ if this is necessary, then we return to step 2 until we have set up the correct model, as evidenced by the forecast error, which should be as small as possible.

- at the last stage it is necessary to calculate the limits of the interval of reliability: $\hat{y}_{t}(\tau) \mp \sigma_{e} \sqrt{1+C(\tau)}$, 
where $C(\tau)$ - calculated individually for models of different orders.

The Holt model is a dynamic process in the form of a linear additive trend:

$\hat{y}_{t}(\tau)=\hat{a}_{0 . t}+\hat{a}_{1 . t} \cdot \tau$

where $\hat{y}_{t}(\tau)$ - prognostic estimate of the level ranges $y_{t+\tau}$, which is calculated at the time $\mathrm{t}$ for steps forward;

-assessment of the current ( $\mathrm{t}$-th) level of the time series;

-assessment of current growth.Recently prediction method in our sample is the method of Holt. It is considered an improved method of exponential smoothing time series. Holt method can detect so-called "mikrotrendy" (trends, which are based on short study period) and build on the basis of their medium and long-term forecasts.

After calculating the predicted values for the various methods, should also analyze the accuracy of forecasts. Generally, the following methods for assessing the accuracy of forecasting:

1) average absolute error:

$M A E=\frac{\sum_{i=n-m+1}^{n}\left|y_{i}-\hat{y}_{i}\right|}{m}$

2) mean-square error:

$M S E=\frac{\sum_{i=n-m+1}^{n}\left(y_{i}-\hat{y}_{i}\right)^{2}}{m}$

3) Root of the mean square error - mean square deviation: $R M S E=\sqrt{\frac{\sum_{i=n-m+1}^{n}\left(y_{i}-\hat{y}_{i}\right)^{2}}{m}}$

4) average percentage error:

$M P E=\frac{\sum_{i=2}^{m}\left(y_{i}-\hat{y}_{i}\right)}{y_{i}} \cdot 100 \%$

5) RMS as a percentage:

$R M S P E=\sqrt{\frac{\sum_{i=n-m+1}^{n}\left(y_{i}-\hat{y}_{i}\right)^{2}}{m} \cdot 100 \%}$

6) absolute average percentage error:

$M A P E=\frac{1}{m} \frac{\sum_{i=2}^{m}\left(y_{i}-\hat{y}_{i}\right)}{y_{i}} \cdot 100 \%$.

Given the importance of these indicators received check the following conditions: the smaller the value calculated values, the higher the quality of the forecast. In practice, these characteristics are used quite often. The use of these indicators gives a qualitative result, if during the investigated period there are no fundamentally new patterns. Interpretation of the last two criteria will conclude overall adequacy and accuracy of the model by comparing them with. System data interpretation criteria is given in the following table (Table. 2).

Table 2. Estimation of forecast accuracy using MAPE, RMSPE criteria, calculations for Ukraine

\begin{tabular}{|c|l|}
\hline MAPE, RMSPE & Accuracy of forecast \\
\hline Less $10 \%$ & High \\
\hline $10 \%-20 \%$ & Good \\
\hline $20 \%-40 \%$ & Satisfactory \\
\hline $40 \%-50 \%$ & Bad \\
\hline More $50 \%$ & Unsatisfactory \\
\hline
\end{tabular}


Using the above methods, move on to the forecasting process six indicators: ratio of required reserves longterm deposits (Res_long), NBU discount rate (Disc_rate), consumer price index (CPI), life expectancy (Life_durat), the level of employment (Employ) tax on interest on deposits (Dep_tax) and the weighted average cost of time deposits (Dep_tax).

Calculate the predictive value for each indicator. The first indicator of reserve requirements, consider longterm deposits (Res_long).The next step will build a forecast using extrapolation method based on the average absolute increment. Before this we must calculate absolute increments (the difference between the present value and the previous one). Thus we find the average absolute gain. After having completed all the necessary interim calculations, you need to add an average absolute increase to each last sample value. Similarly to the method of extrapolation based on the average absolute growth, forward predictive value using extrapolation based on the average growth rate. In the first step, we find the average pace, calculating the average geometric value of this indicator. Then we multiply the corresponding level of the number at the average rate of growth. The predicted values of this indicator, calculated by three methods, are presented in the following table (Table 3 ).

Table 3. Projected value of the mandatory reserve deposits based on the long-term average of the series, the average absolute increase and the average growth rate as II, III, IV quarter 2016 and first quarter 2017, calculations for Ukraine

\begin{tabular}{|l|c|c|c|}
\hline \multirow{2}{*}{ Quarter } & \multicolumn{2}{|c|}{ The assessment value } \\
\cline { 2 - 4 } & $\begin{array}{c}\text { The assessment by average } \\
\text { level range }\end{array}$ & $\begin{array}{c}\text { The assessment by the average } \\
\text { total increment }\end{array}$ & $\begin{array}{c}\text { The assessment by the average } \\
\text { tempo of growth }\end{array}$ \\
\hline II quarter 2016 p. & 1.22 & 2.93 & 0 \\
\hline III quarter 2016 p. & 1.22 & 2.86 & 0 \\
\hline IV quarter 2016 p. & 1.22 & 2.80 & 0 \\
\hline I quarter 2017 p. & 1.22 & 2.73 & 0 \\
\hline
\end{tabular}

During the forecasting, based on the growth curves, the following of the intermediate indicators were obtained (Figures 2, 3).

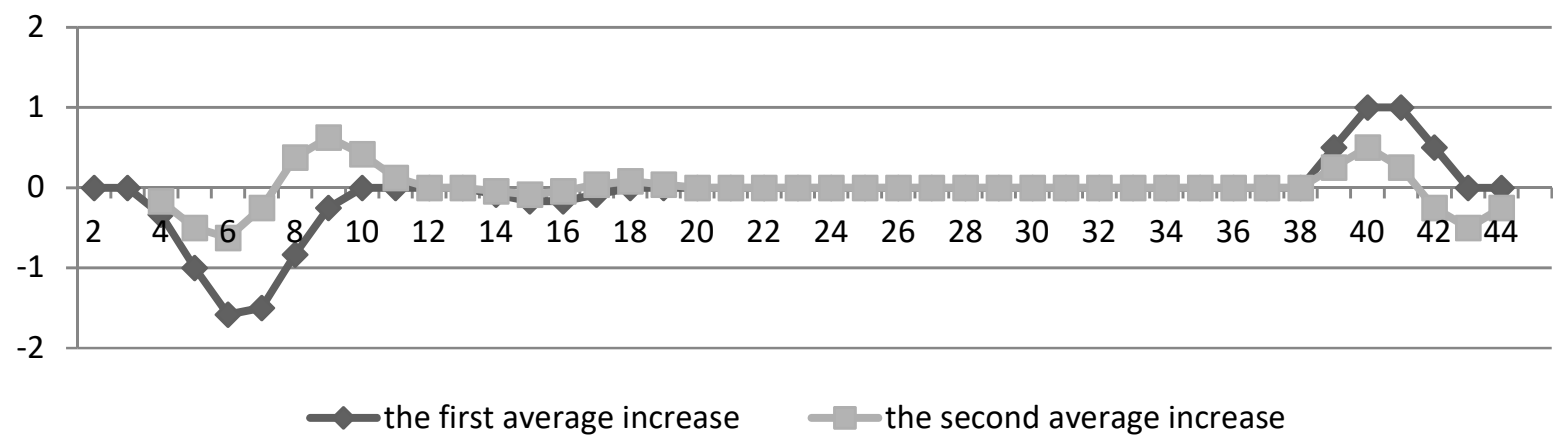

Figure 2. Schedule of first and second average increments for forecasting the norm of obligatory reserve of long-term deposits, calculations for Ukraine

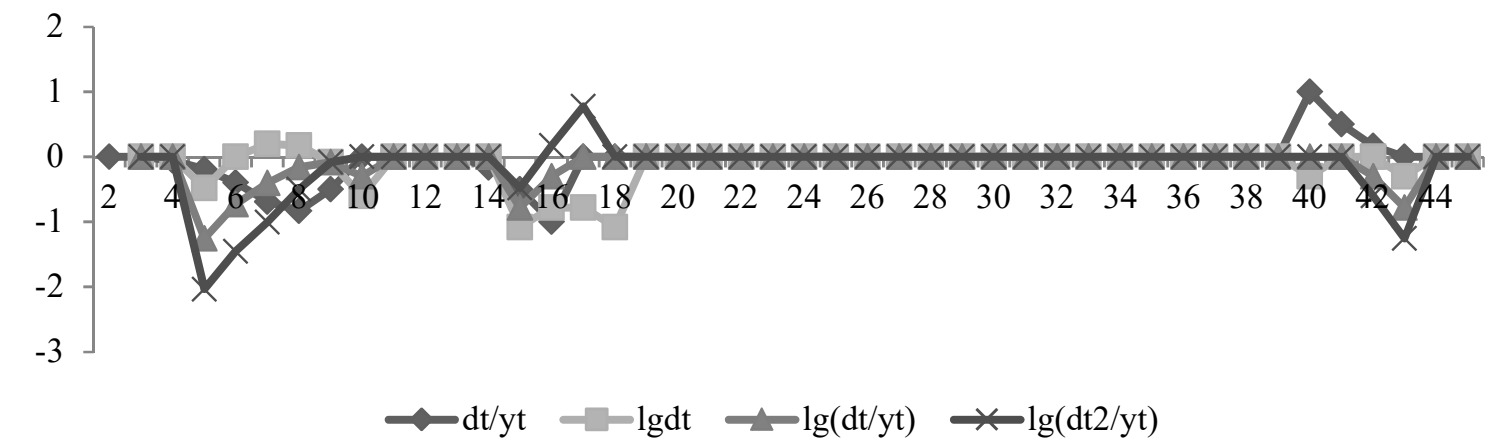

Figure 3. Schedule of characteristics of the growth of the norm of obligatory reserve of long-term deposits, calculations for Ukraine 
The assessment of interest rate on deposits, constructed on the basis of the expression $y=-0,0588 x+2,5737$, has the following form (Table 4)

Table 4. Assessment values of the norm of obligatory reserve of long-term deposits, obtained by extrapolation based on the growth curve (as of II, III, IV quarters 2016 and I quarter 2017), calculations for Ukraine

\begin{tabular}{|c|c|}
\hline Quarter & The assessment value \\
\hline II quarter 2016 & $-0,13$ \\
\hline III quarter 2016 & $-0,19$ \\
\hline IV quarter 2016 p. & $-0,25$ \\
\hline I quarter 2017 p. & $-0,31$ \\
\hline
\end{tabular}

To predict long-term norm of obligatory reservation deposit exponential smoothing method must first find the value of smoothing constant. It is known that for a fast-changing series, it is better to choose a constant smoothing $\alpha 0,2$. Given this condition, the following forecast was constructed (Table 5).

Table 5. The assessment of the norm of obligatory reserve of long-term deposits by the method of exponential smoothing equal to the average and first levels of a series (as of II, III, IV quarters of 2016 and I quarter 2017), calculations for Ukraine

\begin{tabular}{|c|c|c|}
\hline Quarter & $\begin{array}{c}\text { The assessment by the method exponential smoothing } \\
\text { (at the middle level of range) }\end{array}$ & $\begin{array}{c}\text { The assessment by the method exponential } \\
\text { smoothing } \\
\text { (at the first level of range) }\end{array}$ \\
\hline II quarter 2016 & 2.02 & 2.02 \\
\hline III quarter 2016 & 1.61 & 1.61 \\
\hline IV quarter 2016 & 1.29 & 1.29 \\
\hline I quarter 2017 & 1.03 & 1.03 \\
\hline
\end{tabular}

To predict the Brown method, first we find the trend equation for the first values of the input data, and from this trend we obtain a0, a1 and a0, a1, a2 for the first and second order models, respectively. Graphical representation of equations trend and relevant parameters are shown in Fig. 4, 5.

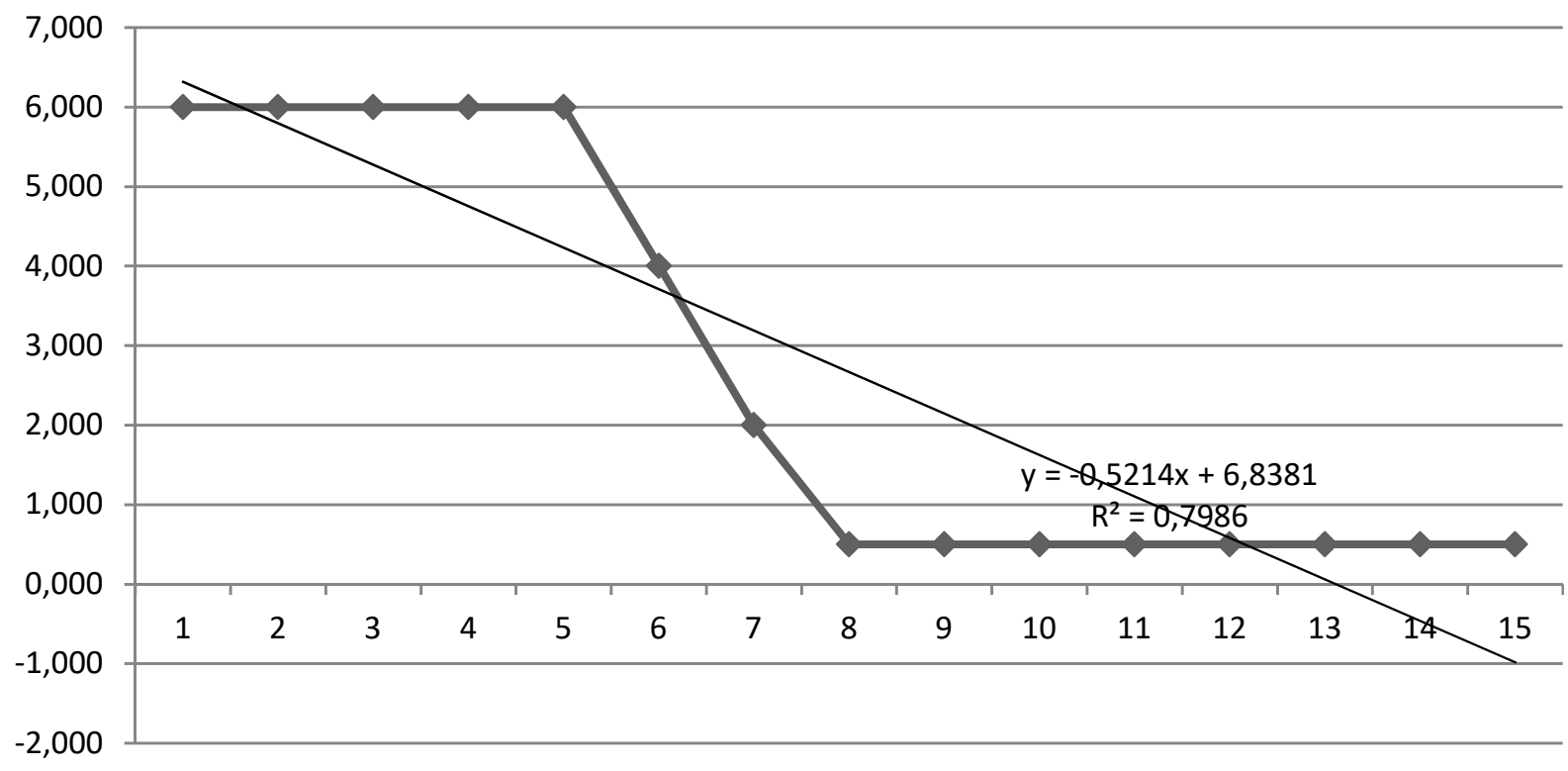

Standard of obligatory reserve of long-term deposits, \%

Figure 4. The graph of the linear trend for the initial data of the mandatory reserve requirement, calculations for Ukraine 


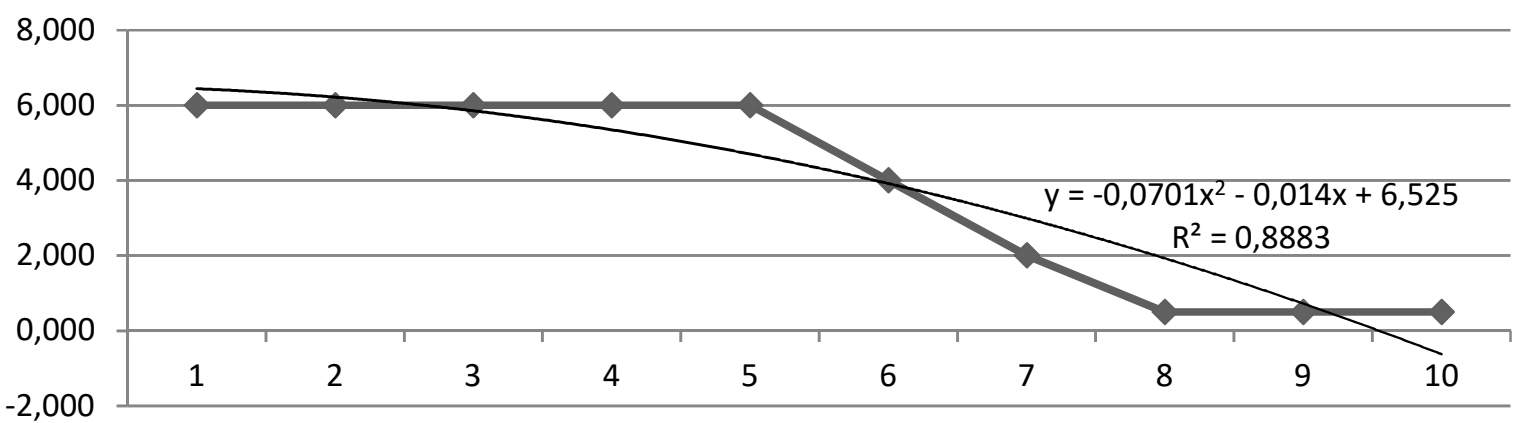

Standard of obligatory reserve of long-term deposits, \%

Figure 5. Graph of polynomial trend for initial data of the norm of obligatory reserve of long-term deposits, calculations for Ukraine

The projected values of the norm for obligatory reserve of long-term deposits, obtained by Brown's first and second order, are presented in Table. 5, 6

Table 6. The assessment and intervals of reliability of the norm of obligatory reserve of long-term deposits by the Brown method of first order in II, III, IV quarters of 2016 and I quarter 2017, calculations for Ukraine

\begin{tabular}{|l|c|c|c|c|}
\hline \multicolumn{5}{|c|}{ Braun Model 1 } \\
\hline Quarter & The assessment & \multicolumn{2}{|c|}{ Intervals of reliability } & \multirow{2}{*}{ Standard deviation } \\
\hline II quarter 2016 & -2.34 & -8.78 & 4.10 & \multirow{3}{*}{3.22} \\
III quarter. 2016 & -2.59 & -9.08 & 3.90 & 3.71 \\
IV quarter 2016 & -2.83 & -9.38 & 3.51 & \\
\hline I quarter 2017 & -3.08 & -9.67 & \\
\hline
\end{tabular}

Table 7. $\mathrm{t}$ and reliability intervals norm of obligatory reservation by long-term deposits Brown second order as II, III, IV quarter 2016 and first quarter 2017, calculations for Ukraine

\begin{tabular}{|l|c|c|c|c|}
\hline \multicolumn{4}{|c|}{ Braun Model 1 } \\
\hline \multicolumn{1}{|c|}{ Quarter } & The assessment & Intervals of reliability & \multirow{2}{*}{ Standard deviation } \\
\hline II quarter 2016 & 1.25 & -2.73 & 5.24 & \multirow{3}{*}{3.59} \\
\hline III quarter. 2016 & 1.18 & -2.87 & 5.23 & 5.22 \\
\hline IV quarter 2016 & 1.10 & -3.02 & 5.22 & \\
\hline I quarter 2017 & 1.02 & -3.18 & 5 \\
\hline
\end{tabular}

Using the Holt method for prediction. the following results were obtained (Table 7).

Table 8. Forecast norm of mandatory reserve deposits by term as Holt II, III, IV quarter 2016 and first quarter 2017, calculations for Ukraine

\begin{tabular}{|c|c|}
\hline Quarter & The assessment value \\
\hline II quarter 2016 & -0.50 \\
\hline III quarter 2016 & -0.55 \\
\hline IV quarter 2016 & -0.60 \\
\hline I quarter 2017 & -0.64 \\
\hline
\end{tabular}

Table 9. Analysis of the accuracy of the predictive values of the norm of obligatory reservation long-term deposits, calculations for Ukraine

\begin{tabular}{|c|c|c|c|c|c|c|}
\hline \multirow{2}{*}{ The assessment } & \multicolumn{6}{|c|}{ Indicators } \\
\hline & $M A E$ & $M S E$ & RMSE & $R M S P E$ & $M P E$ & $M A P E$ \\
\hline $\begin{array}{l}\text { Extrapolation based on the middle level of } \\
\text { the series }\end{array}$ & 1.78 & 3.16 & 1.78 & $59.26 \%$ & $59.26 \%$ & $59.26 \%$ \\
\hline $\begin{array}{l}\text { Extrapolation based on average absolute } \\
\text { growth }\end{array}$ & 0.17 & 0.03 & 0.19 & $6.22 \%$ & $5.68 \%$ & $5.68 \%$ \\
\hline Extrapolation based on average growth rate & - & - & - & - & - & - \\
\hline Extrapolation based on the growth curve & 3.22 & 10.37 & 3.22 & $107.33 \%$ & $107.31 \%$ & $107.31 \%$ \\
\hline
\end{tabular}


Table 9. Analysis of the accuracy of the predictive values of the norm of obligatory reservation long-term deposits, calculations for Ukraine

\begin{tabular}{|c|c|c|c|c|c|c|}
\hline \multirow{2}{*}{ The assessment } & \multicolumn{6}{|c|}{ Indicators } \\
\hline & $M A E$ & $M S E$ & RMSE & $R M S P E$ & $M P E$ & $M A P E$ \\
\hline $\begin{array}{l}\text { Exponential method. Smoothing (in the } \\
\text { middle level) }\end{array}$ & 1.51 & 2.42 & 1.55 & $51.83 \%$ & $50.35 \%$ & $50.35 \%$ \\
\hline $\begin{array}{l}\text { Exponential method. Smoothing (for the } \\
\text { first level) }\end{array}$ & 1.51 & 2.42 & 1.55 & $51.82 \%$ & $50.35 \%$ & $50.35 \%$ \\
\hline Braun Model 1 & 5.71 & 32.69 & 5.72 & $190.60 \%$ & $190.38 \%$ & $190.38 \%$ \\
\hline Braun Model 2nd order & 1.86 & 3.47 & 1.86 & $62.08 \%$ & $62.01 \%$ & $62.01 \%$ \\
\hline Model Holt & 3.57 & 12.78 & 3.57 & $119.16 \%$ & $119.15 \%$ & $119.15 \%$ \\
\hline
\end{tabular}

Table 10. Analysis of precision models for Theil coefficient received predictive values of the norm of obligatory reservation long-term deposits, calculations for Ukraine

\begin{tabular}{|c|c|c|c|c|c|}
\hline \multirow{2}{*}{ The assessment } & \multicolumn{5}{|c|}{ Indicators } \\
\hline & $U$ & $U^{M}$ & $U^{S}$ & $U^{C}$ & Сума \\
\hline $\begin{array}{l}\text { Extrapolation based on the middle level of } \\
\text { the series } \\
\text { Forecast }\end{array}$ & 0.658 & 1.00 & 0.00 & 0.00 & 1 \\
\hline $\begin{array}{l}\text { Extrapolation based on average absolute } \\
\text { growth }\end{array}$ & 0.032 & 0.83 & 0.22 & - & 1 \\
\hline Extrapolation based on average growth rate & - & - & - & - & - \\
\hline Extrapolation based on the growth curve & 2.595 & 1.00 & 0.00 & - & 1 \\
\hline \multirow{2}{*}{ The assessment } & \multicolumn{5}{|c|}{ Indicators } \\
\hline & $U$ & $U^{M}$ & $U^{S}$ & $U^{C}$ & Сума \\
\hline $\begin{array}{l}\text { Exponential method. Smoothing (in the } \\
\text { middle level) }\end{array}$ & 0.474 & 0.94 & 0.07 & - & 1 \\
\hline $\begin{array}{l}\text { Exponential method. Smoothing (for the } \\
\text { first level) }\end{array}$ & 0.474 & 0.94 & 0.07 & - & 1 \\
\hline Braun Model 1 & 1.026 & 1.00 & 0.00 & - & 1 \\
\hline Braun Model 2nd order & 0.727 & 1.00 & 0.00 & - & 1 \\
\hline Model Holt & 2.192 & 1.000 & 0.00 & - & 1 \\
\hline
\end{tabular}

According to the estimated estimates, we can conclude that the most accurate forecast is extrapolation based on the average absolute increase, the MAPE and RMSPE criteria are 5.68\% and $6.22 \%$, respectively, indicating a high accuracy of the calculated forecast. This assumption confirms the value of the calculated Tayle criterion 0.032 .

After analyzing all the indicators and making the assessment for 4 quarters, we can conclude that to predict most indicators, extrapolation based on average absolute growth is best suited. The assessment for all indicators is presented in Table 11.

Table 11. Forecast for incoming data for 4 quarters, calculations for Ukraine

\begin{tabular}{|c|c|c|c|c|c|}
\hline Indicator & Predictive method & $\begin{array}{l}\text { II quarter } \\
2016\end{array}$ & III quarter 2016 & IV quarter 2016 & I quarter 2017 \\
\hline $\begin{array}{l}\text { The reserve requirement for } \\
\text { long-term deposits, } \\
\text { Res_long, } \%\end{array}$ & $\begin{array}{l}\text { Extrapolation based on average absolute } \\
\text { growth }\end{array}$ & 2.93 & 2.86 & 2.8 & 2.73 \\
\hline $\begin{array}{l}\text { NBU discount rate, } \\
\text { Disc_rate, } \%\end{array}$ & Extrapolation based on average growth rate & 19.5 & 19.02 & 17.54 & 16.08 \\
\hline $\begin{array}{l}\text { Consumer price index, } \\
\text { CPI, } \%\end{array}$ & Braun Model 2nd order & 34.65 & 36.9 & 39.19 & 41.5 \\
\hline $\begin{array}{l}\text { Interest tax on deposits, } \\
\text { Dep_tax, } \%\end{array}$ & $\begin{array}{l}\text { Extrapolation based on average absolute } \\
\text { growth }\end{array}$ & 18.41 & 18.82 & 19.23 & 19.64 \\
\hline Life expectancy, Life_durat, & $\begin{array}{l}\text { Extrapolation based on average absolute } \\
\text { growth }\end{array}$ & 71.4 & 71.5 & 71.6 & 71.7 \\
\hline $\begin{array}{l}\text { Employment rate, } \\
\text { Employ,\% }\end{array}$ & Extrapolation based on average growth rate & 55.6 & 55.6 & 55.6 & 55.6 \\
\hline $\begin{array}{l}\text { Average weighted value of } \\
\text { term deposits, Dep_rate, } \%\end{array}$ & Braun Model 1 & 13.9 & 10.4 & 10.3 & 9.9 \\
\hline
\end{tabular}


Considering the above estimates are calculated, we can make a function of supply and demand. The equation for predicting the equilibrium price of the deposit market in Ukraine in the future (II, III and IV quarters of 2016 and I quarter of 2017) is as follows:

$$
\begin{aligned}
& 146372.1+17954.1 \cdot D R_{\text {prog }}-49722.24 \cdot 1.3+14422.86 \cdot 11.35+3.48 E^{-14} \cdot e^{13,93}= \\
& =-9004898+18613.21 \cdot D R_{\text {prog }}+44999.38 \cdot 70.04-4310.705 \cdot 3.86+104871 \cdot 58.04
\end{aligned}
$$

Results showed forecasting lower average deposit rate for II - IV quarter. 2016 and I quarter 2017 from 13.9\% to $9.9 \%$, which does not correspond to the calculated level of equilibrium rate. Therefore, we can speak about the prospect of achieving an equilibrium rate only from 2018.

\section{Conclusions}

The results of the analysis of existing methodologies to assess market demand and supply was found that they are more used to analyze the equilibrium in the credit market. In order to use these approaches to study the deposit market, they need to be adapted by selecting relevant factors and a dependent variable. In addition, the choice of a model should definitely pay attention to the specifics of the banking system, its legal security, availability and accessibility to necessary information resources. When forecasting demand, supply and equilibrium price of the deposit market Ukraine should take into account the time lag found in 2 quarters. The selection of forecasting methods deposit market conditions Ukraine to consider empirical evidence of their effectiveness in other countries the national accounting system and financial sector reform course, the time lag. Forecast for the period II-IV quarter 2016 and I quarter 2017 showed lower average deposit rate from $13.9 \%$ to $9.9 \%$, as evidenced by current statistics NBU.

\section{References}

1. Bernet B., (2009). Design, Structure, and Implementation of a Modern Deposit Insurance Scheme. SUERF Studies, 5, 40.

2. Bollen R. (2006). What is a Deposit (and Why Does It Matter)? Journal of Banking and Finance Law and Practice, 17, 21.

3. Collender, Robert N., Shaffer, Sherrill L. (2014). Local Bank Office Ownership, Deposit Control, Market Structure, and Economic Growth. Economic Research Service, USDA Journal of Banking \& Finance, 27(1), 27-57.

4. Demirguc-Kunt, A., Sobaci, T. (2015). Deposit Insurance Around the World: A Comprehensive Analysis and Database [Online]. Retrieved from https://www2.bc.edu/edwardkane/DepositInsuranceAroundWorld.pdf.

5. Dick, A. (2002). Demand Estimation and Consumer Welfare in the Banking Industry. P. 38.

6. Kanoh, S., Pumpaisanchai, C. (2006). Listening to the Market: Estimating Credit Demand and Supply from Survey Data. Institute of Economic Research Hitotsubashi University. P. 37.

7. Koetter, M., Poghosyan, T. (2009). The identification of technology regimes in banking: Implications for the market power-fragility nexus. Journal of Banking \& Finance, 33, 1413-1422.

8. Leon, F. (2014). Measuring competition in banking: A critical review of methods. CERDI: Etudes et Documents, 12, $44 \mathrm{p}$.

9. Lyeonov, S., Didenko, I. (2017) Assessment of demand, supply and equilibrium price on the deposit market of Ukraine. Financial Markets, Institutions and Risks, 1(2), 5-13.

10. Panzar, J. C., Rosse, J. (1987). Testing for Monopoly Equilibrium. Journal of Industrial Economics, 25, 443-456.

11. Sovago, S. (2011). Identifying supply and demand in the Hungarian corporate loan market. MNB Occasional papers, 94, P. 28.

12. Vasylieva, T., Lyeonov, S., Buriak, A. (2015). Systemically important domestic banks: an indicator-based measurement approach for the Ukrainian banking system, Financial Markets, Institutions and Risks, 24(6), 715-728.

13. Xavier Vives (2001). Competition in the changing world of banking. Oxford Review of Economic Policy, $17(4), 535-547$. 